\title{
Jogos de empresas aplicados à formação profissional para o setor portuário: 0 Caso do Jogo do TECON
}

Suellem Deodoro Silva

Pítias Teodoro

Márcio de Almeida D'Agosto

\section{Resumo}

O presente trabalho teve como objetivo demonstrar que o Jogo do TECON é adequado para apoiar o processo de formação profissional para o setor portuário. Para atendê-lo realizou-se uma pesquisa exploratória e experimental cujos procedimentos foram à aplicação do jogo do TECON seguida da aplicação de questionários. $\mathrm{O}$ grupo selecionado para o experimento foi à turma do 4 o período do curso Técnico em Porto do CEFET/Itaguaí - RJ. Por meio do confronto entre o resultado obtido pelos alunos no Jogo do TECON (prática simulada) e suas respostas aos questionários (teoria) foi possível identificar alguns padrões nas repostas dos questionários que podem ser associados ao resultado do jogo, indicando aderência entre teoria e prática. É possível afirmar que o ambiente simulado pelo Jogo do TECON possui requisitos para aprimorar o processo de formação profissional para o setor portuário, entretanto, em função das limitações do experimento não foi possível generalizar este resultado.

Palavras-chaves: Jogos de empresa, Metodologia de ensino, Terminais de contêineres, Jogo do TECON.

\section{Abstract \\ Business games applied to training for port sector: The case of the Tecon's Game}

The study aimed demonstrate that the TECON'S Game is adequate to support the process of training for the port sector. To answer it was performed an exploratory and experimental procedures which were applied to the TECON'S Game followed by questionnaires. The group selected for the experiment was the class of the 4th period of the course Technician Port CEFET / Itaguaí - RJ. Through the comparison between the results obtained by students in the TECON'S Game (simulated practice) and their responses to questionnaires (theory) it was possible to identify some patterns in the responses of questionnaires that can be associated with the outcome of the game, indicating adherence between theory and practice. It can be argued that the simulated environment by TECON'S Game has requirements to improve the training process for the port sector, however, due to the limitations of the experiment was not possible to generalize this result.

Keywords: Business games, Teaching methodology, Container terminals, TECON'S Game 


\section{Introdução}

Com o crescimento do comércio mundial ao longo das últimas décadas, a organização portuária tem sido alterada com o intuito de fomentar a produtividade e competitividade do setor. Dentre os terminais portuários, aquele que tem apresentado maior aumento no volume de movimentação de cargas é o terminal de contêineres, cuja utilização se justifica em função das especificidades de vários tipos de cargas: são frágeis, perecíveis, precisam ser unitizadas e ou demandam o uso de mais de um modo de transporte.

O relatório Panorama Aquaviário, da Agência Nacional de Transportes Aquaviários do Ministério dos Transportes, a partir de dados de 2010 sobre o comércio internacional brasileiro, informa que "nas exportações, o volume transportado por via marítima representou 96\% do total, enquanto nas importações o índice alcançou $88 \%$. Ao se analisar o fluxo comercial por valor (US\$ FOB), percebe-se que essa participação foi de $83 \%$ do montante exportado e de $73 \%$ do importado".

Aproximadamente $10 \%$, de um total de 20 milhões de toneladas da carga movimentada no Brasil no 10 trimestre de 2012, foram realizadas com a utilização de contêineres. Foram movimentados 1,9 milhões de TEUs, crescimento de 8,0 \% em relação ao primeiro trimestre de 2011. Em termos de peso bruto, houve um aumento de 7,1\% em relação ao mesmo período do ano anterior (MT, 2012).

Uma abordagem educacional que auxilie na compreensão do funcionamento do setor portuário, especificamente de terminais de contêineres, que considere os equipamentos específicos e a área dedicada à movimentação e armazenamento de contêineres, pode contribuir para aumentar a qualificação da mão de obra, logo para o aumento da competitividade do setor portuário brasileiro. Com este propósito, este trabalho apresenta um jogo de empresas como método de apoio ao processo de ensino-aprendizagem para qualificação de técnicos e ou tecnólogos na área de planejamento operacional de terminais de contêineres: o Jogo do TECON.

A utilização de um jogo de empresa possibilita aos usuários - alunos e professores vivenciarem decisões do dia a dia de um setor e ou da empresa simulada, bem como as decorrências dessas opções. O propósito da simulação é uma aproximação entre teoria e prática sem o tempo, custos e, eventualmente, os riscos que a atividade que está sendo simulada poderia gerar se o treinamento fosse realizado diretamente no ambiente de trabalho.

Nesse contexto, o presente trabalho tem como objetivo "demonstrar que o Jogo do TECON é adequado para apoiar o processo de ensino-aprendizagem na área de planejamento operacional de terminais de contêineres".

Para atendê-lo, no desenvolvimento deste trabalho, é apresentado o Jogo do TECON e os resultados obtidos em sua utilização como ferramenta de apoio ao processo de ensinoaprendizagem. A aplicação do jogo foi realizada junto aos alunos do $4^{\circ}$ período do curso Técnico 
em Portos do CEFET (Centro Federal de Educação Tecnológica), disciplina: Operação de Contêiner, localizado no município de Itaguaí - RJ, Brasil, e evidencia sua contribuição na formação de profissionais para o setor portuário.

Quanto aos procedimentos metodológicos pode-se classificar o presente estudo como uma aplicação exploratória e experimental (Silva e Menezes, 2001). Em sua consecução, após a aplicação do jogo, foi utilizado questionário estruturado para coleta de dados, cujas respostas foram tabuladas e apresentadas por meio de tabelas e gráfico.

Além desta introdução e das referências bibliográficas, o trabalho encontra-se dividido em 6 itens. No item 1 apresenta-se o ensino na área de portos no Brasil. No item 2 apresenta-se a relação entre ciclo de aprendizagem vivencial e jogos de empresas. O Jogo do TECON é apresentado no item 3. No item 4 tem-se a descrição da aplicação do Jogo do TECON junto aos alunos que foram submetidos ao treinamento com o uso do Jogo do TECON. No item 5 têm-se as análises qualitativas e quantitativas da aplicação. Finalmente, no item 6 têm-se as considerações finais, limitações e sugestões para trabalhos futuros.

\section{Ensino na área de portos no Brasil}

No Brasil, a formação na área de portos se dá basicamente em dois níveis: o técnico e o tecnológico. Em nível de graduação também é possível obter formação na área portuária, porém, não são cursos dedicados ao setor e sim cursos como de engenharia civil ou administração que possuem disciplinas que tratam de terminais portuários e comércio exterior.

O curso técnico em portos segue o Catálogo Nacional de Cursos Técnicos (CNCT, 2008) e capacita os profissionais para atuarem na operação portuária, no agenciamento de embarcações, nos procedimentos de importação/exportação, com base no regulamento aduaneiro e na gestão e operação dos equipamentos portuários.

Já o curso tecnológico em gestão portuária, segue o Catálogo Nacional de Cursos Superiores de Tecnologia (CNCST, 2006), e capacita os profissionais a atuarem na gestão de organizações portuárias desempenhando funções estratégicas, administrativas e também operacionais, assim como relações de interface logística da cadeia de suprimentos.

As definições das atribuições dos profissionais da área técnica em portos e da área tecnológica em portos demonstram que os cursos de nível técnico estão voltados predominantemente para uma formação em nível operacional, enquanto os cursos de nível tecnológico para uma formação predominantemente em nível tático.

Pesquisa documental, por meio de consulta e levantamento de dados no portal do Ministério da Educação (MEC, 2012), possibilitou identificar as principais instituições de ensino que oferecem cursos técnicos em portos e cursos tecnológicos em gestão portuária, no Brasil. 
Quadro 1 - Instituições que oferecem os cursos Técnicos em Portos e ou Tecnológicos em Gestão Portuária no Brasil.

\begin{tabular}{|c|c|c|c|c|}
\hline \multicolumn{2}{|r|}{ Nome da Instituição } & Cidade & Total de & Matriz curricular \\
\hline \multirow{2}{*}{ 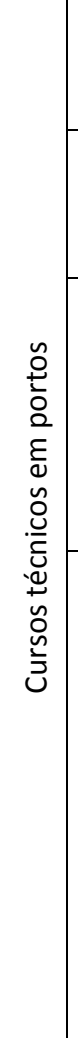 } & $\begin{array}{l}\text { Centro Federal de } \\
\text { Educação } \\
\text { Tecnológica - } \\
\text { CEFET/Itaguaí }\end{array}$ & $\begin{array}{c}\text { Cariacica - } \\
\text { ES }\end{array}$ & 4 & $\begin{array}{l}\text { Mod.2 - op. de carga a granel; afretamento de } \\
\text { navios e agenciamento marítimo. } \\
\text { Mod.3 - op. de carga geral; automação, estruturas } \\
\text { mecânicas; desempenho operacional e custos. } \\
\text { Mod.4 - op. de contêiner; logística; qualidade total; } \\
\text { planejamento de controle da manutenção. }\end{array}$ \\
\hline & $\begin{array}{c}\text { Serviço Nacional de } \\
\text { Aprendizagem } \\
\text { Industrial - SENAI/SC }\end{array}$ & Itajaí - SC & 4 & $\begin{array}{l}\text { Mod.1 - estrutura e funcionamento de terminais } \\
\text { portuários; gestão de processos. } \\
\text { Mod.2 - gestão de cargas; logística portuária; } \\
\text { sistemática de importação e exportação. } \\
\text { Mod.3 - legislação aduaneira; planejamento, } \\
\text { controle e manutenção de equipamentos } \\
\text { portuários. }\end{array}$ \\
\hline 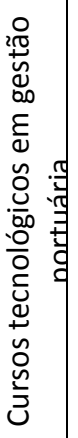 & $\begin{array}{c}\text { Faculdade } \\
\text { Metropolitana da } \\
\text { Grande Recife - } \\
\text { UNESJ }\end{array}$ & $\begin{array}{l}\text { Jaboatão } \\
\text { dos } \\
\text { Guararapes } \\
\text { - PE }\end{array}$ & 4 & $\begin{array}{l}\text { Mod.1 - sistema portuário. } \\
\text { Mod.2 - sistemas de transporte e armazenamento; } \\
\text { legislação aduaneira; operações portuárias. } \\
\text { Mod.3 - gestão portuária I; logística operacional. } \\
\text { Mod.4 - gestão portuária II; gestão fin. e } \\
\text { orçamentária. }\end{array}$ \\
\hline 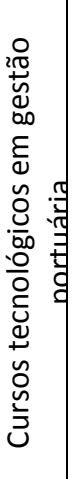 & $\begin{array}{l}\text { Centro Universitário } \\
\text { Vila Velha - UVV }\end{array}$ & $\begin{array}{c}\text { Vila Velha - } \\
\text { ES }\end{array}$ & 5 & $\begin{array}{l}\text { Mod.1 - planejamento do sist.. portuário brasileiro. } \\
\text { Mod.2 - legislação aduaneira e regimes especiais; } \\
\text { mercado e custos portuários. } \\
\text { Mod.3 - logística e transportes multimodais; } \\
\text { modelo de gestão nos portos. } \\
\text { Mod.4 - adm. estratégica; gestão de porto seco } \\
\text { cargas gerais e contêineres; armazéns e cargas. }\end{array}$ \\
\hline
\end{tabular}

DOI: Em andamento. 


\begin{tabular}{|c|c|c|c|c|}
\hline \multirow{2}{*}{\multicolumn{2}{|c|}{ stituição }} & \multicolumn{3}{|c|}{ Continuação do Quadro 1} \\
\hline & & Cidade & $\begin{array}{l}\text { Total de } \\
\text { módulos }\end{array}$ & $\begin{array}{c}\text { Matriz curricular } \\
\text { (Principais disciplinas por módulo) }\end{array}$ \\
\hline \multirow{4}{*}{ 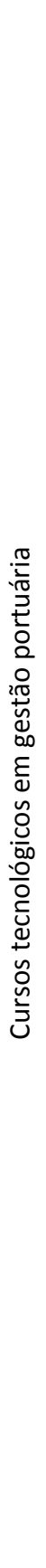 } & $\begin{array}{c}\text { Universidade } \\
\text { Paulista - UNIP }\end{array}$ & $\begin{array}{c}\text { São Paulo - } \\
\text { SP }\end{array}$ & 4 & $\begin{array}{l}\text { - equipamentos e cargas; gestão de operações } \\
\text { portuárias; legislação aduaneira e portuária; } \\
\text { logística e transporte; sistemática de importação e } \\
\text { exportação; tópicos especiais em gestão portuária. }\end{array}$ \\
\hline & $\begin{array}{c}\text { Centro Universitário } \\
\text { Monte Serrat- } \\
\text { UNIMONTE }\end{array}$ & Santos - SP & 4 & $\begin{array}{l}\text { Mod.1 - introdução a logística; gestão portuária; } \\
\text { comércio exterior. } \\
\text { Mod.3 - movimentação e armazenagem; gestão e } \\
\text { análise de custos. } \\
\text { Mod.4 - sistemática de exportação e importação; } \\
\text { planejamento de operação e manutenção de } \\
\text { terminais portuários; sistema portuário brasileiro e } \\
\text { suas interfaces; operações de terminais. }\end{array}$ \\
\hline & $\begin{array}{c}\text { Universidade } \\
\text { Católica de Santos- } \\
\text { UNISANTOS }\end{array}$ & Santos - SP & 4 & $\begin{array}{l}\text { Mod.2 - cargas I; gestão de armazenagem; portos e } \\
\text { terminais. } \\
\text { Mod.3 - cargas II; logística internacional; transporte } \\
\text { marítimo. } \\
\text { Mod.4 - planejamento portuário; gestão portuária; } \\
\text { terminais especializados. }\end{array}$ \\
\hline & $\begin{array}{l}\text { Universidade do } \\
\text { Vale do Itajaí - } \\
\text { UNIVALI }\end{array}$ & Itajaí - SC & 5 & $\begin{array}{l}\text { Mod.1 - introdução ao sistema portuário. } \\
\text { Mod.2 - gestão de armazéns; gerenciamento de } \\
\text { custos; transporte marítimo. } \\
\text { Mod.3 - terminais e portos I; logística internacional. } \\
\text { Mod.4 - legislação aduaneira; terminais e portos II. } \\
\text { Mod.5 - gestão de RH; terminais e portos III. }\end{array}$ \\
\hline
\end{tabular}

Fonte: Elaboração Própria a partir de CNCST (2006), CNCT (2008), MEC (2012), IFMA (2012), IFES (2012), CEFET (2012), SENAI/SC (2012), UNESJ (2012), UNIP (2012), UNIMONTE (2012), UNISANTOS (2012), UNIVALI (2012), UVV(2012). 
Conforme apresentado no Quadro 1, foram identificadas 10 instituições que oferecem cursos específicos para a formação técnica e tecnológica na área de portos. As instituições que oferecem cursos técnicos (4) não oferecem cursos tecnológicos (6). De um modo geral, a maioria das instituições de ensino (8), sejam elas de nível técnico ou tecnológico, dividem a matriz curricular de seus cursos em 4 módulos, o que implica em cursos com duração de 2 anos

Verifica-se que, além da baixa oferta de cursos específicos na área portuária ainda há sua concentração em áreas de influência dos maiores portos brasileiros: Três cursos são oferecidos no estado de São Paulo, onde se localiza o maior porto brasileiro (Porto de Santos), dois no Espírito Santo (Porto de Vitória) e dois em Santa Catarina (Porto de Paranaguá). Um curso é oferecido no estado do Rio de Janeiro (Portos do Rio de Janeiro e de Itaguaí), um no estado do Maranhão (Porto de Itaqui) e um no Estado de Pernambuco (Porto de Suape).

Identificados os cursos de técnicos e tecnológicos oferecidos atualmente no Brasil, por meio de consultas aos websites das instituições, buscou-se identificar as metodologias de ensino que são utilizadas nesse curso e as principais disciplinas que compõem a matriz curricular.

As metodologias de ensino são procedimentos didáticos utilizados pelos professores com o intuito de criar condições favoráveis ao processo de ensino-aprendizagem. De um modo geral, as abordagens que tratam do processo de ensino-aprendizagem podem ser classificadas em dois grandes grupos: 1) tradicionais e 2) participativas.

De acordo com (Silva, 2010), dentre as principais metodologias tradicionais destacam-se as aulas expositivas, a resolução de exercícios, o estudo de textos, o estudo dirigido e os seminário. Já dentre as metodologias participativas destacam-se o estudo de caso, as visitas técnicas, as soluções de problemas, os softwares de simulação e os jogos de empresas.

A partir da pesquisa documental realizada com as instituições apresentadas na Tabela 1 pode-se concluir que embora exista um amplo leque de metodologias a disposição dos professores dos cursos na área de portos, apenas as seguintes abordagens são utilizadas no processo de ensino-aprendizagem: 1) aula expositiva e seminários (tradicionais) e ou estudo de casos e visitas técnicas (participativas).

\section{Ciclo de aprendizagem vivencial e jogos de empresas}

Para enriquecer a formação profissional não basta transmitir para os alunos os conhecimentos técnicos sobre o setor em estudo, é necessário, ainda, estabelecer condições para que este aluno construa o seu próprio conhecimento e assim tenha uma aprendizagem efetiva (Silva, 2010). 


\subsection{Ciclo de aprendizagem vivencial (C.A.V.)}

Kolb (1984) afirma que a "aprendizagem é o processo pelo qual o conhecimento é criado através da transformação da experiência" em um ciclo de quatro fases: 1) Experiência concreta; 2) Observação reflexiva; 3) Conceituação abstrata e 4) Experimentação ativa.

A primeira fase ocorre por meio de uma ação que se desdobra em efeitos quando o indivíduo experimenta o aprendizado por meio da vivência. A segunda fase leva o indivíduo a refletir sobre a experiência ocorrida e deve desenvolver sua capacidade de antecipar o resultado da ação experimentada, se a mesma for realizada nas mesmas circunstâncias. A terceira fase leva o indivíduo a ter a capacidade de criar conceitos que integrem suas observações de forma lógica e generalizar a ação experimentada. Na quarta fase, o indivíduo deve expandir o uso do conhecimento gerado ao tomar decisões e ou resolver problemas a partir do aprendizado em outras situações.

Pode-se definir que a aprendizagem vivencial é um processo por meio do qual o conhecimento é criado pela transformação de experiência e que, de acordo com Kolb (1984), ocorre a partir de seis suposições: 1) A aprendizagem é um processo, não um resultado; 2) Deriva da experiência; 3) Exige que um indivíduo solucione demandas dialeticamente opostas; 4) É holístico e integrativo; 5) Requer interação entre uma pessoa e um ambiente e 6) Resulta em criação de conhecimento.

Para Silva (2010), a utilização de uma metodologia de ensino participativa em cursos na área de portos, tal como os jogos de empresas, tem potencial para auxiliar o aluno a completar o C.A.V. à medida que o ambiente organizacional simulado por esta metodologia possui aderência às suas fases.

\subsection{Jogos de empresas}

Os jogos de empresas são exercícios experimentais e competitivos que representam, de forma simplificada (quantitativa e ou qualitativa), atividades vivenciadas no dia a dia do mundo dos negócios, no qual os participantes são estimulados a tomar decisões em empresas virtuais. Segundo Sauaia (2008), se baseiam num modelo de simulação em que as características de uma determinada empresa e do ambiente que a envolve, são retratadas de forma aproximada às situações reais, para que decisões sejam postas em prática. Num jogo de empresas, os participantes exercitam a análise de problemas empresariais e praticam a tomada de decisão em organizações simuladas descritas em relatórios operacionais e financeiros.

Dois aspectos não exclusivos valorizam a dinâmica dos jogos de empresas: a competição e a experimentação. $O$ primeiro é a oportunidade de aproveitar a dinâmica de ter outras pessoas tentando conseguir a mesma coisa. Essa competição, sengundo Lewis e Maylor (2007), é quase sempre benéfica para a experiência do participante do jogo, criando uma pressão adicional análoga a de um mercado competitivo. O segundo é a oportunidade que o jogo gera 
possibilitando ver e comparar os efeitos do emprego de uma ou outra estratégia.

Os jogos de empresas podem ser utilizados como ferramenta de treinamento profissional, didática ou de pesquisa. Quando usado como ferramenta de treinamento profissional, o objetivo do jogo de empresas é desenvolver habilidades para o processo de tomada de decisão. Quando usado como ferramenta didática, o objetivo é transmitir conhecimentos específicos a partir da prática experimental e quando for usado com uma ferramenta de pesquisa, o objetivo é descobrir soluções para problemas empresariais por meio da aplicação de teorias gerenciais e ou econômicas, combinadas com estudos comportamentais dos participantes frente às situações propostas no jogo (SILVA, 2010).

Embora uma das características básicas de um jogo de empresa esteja relacionada com a simulação da realidade, para Tanabe (1977), as simulações existentes nos jogos de empresas são sempre mais simples que a do mundo real. Além do fato de não ser possível à obtenção de um conhecimento completo da realidade, o jogo deve ser relativamente fácil de ser processado para que permita que os participantes sejam capazes de identificar as relações de causa e efeito de suas tomadas de decisões.

Para a aplicação de um jogo de empresa é necessário à existência de três elementos principais: 1) O participante (aluno), 2) O instrutor (professor) e 3) O processador. O participante compreende um grupo de pessoas que devem estudar o ambiente simulado e pesquisar as estratégias mais adequadas para o processo de tomada de decisão. $O$ instrutor é a pessoa responsável por coordenar a aplicação do jogo e propor discussões, análises e avaliações das decisões tomadas pelos participantes. O processador é a área do jogo onde são registradas as decisões (módulo do participante) e realizados cálculos e armazenamento de todos os dados gerados durante os ciclos gerenciais simulados (módulo do professor), com o intuito de definir os resultados do jogo e permitir a análise das decisões, numa associação de causa e efeito.

Os jogos de empresas podem ser classificados de acordo com: a área de atuação, o processamento das informações, a abrangência, a estrutura do trabalho, a natureza das variáveis e o processo de tomada de decisão. A Figura 1 apresenta as classificações e subclassificações de um jogo de empresa 


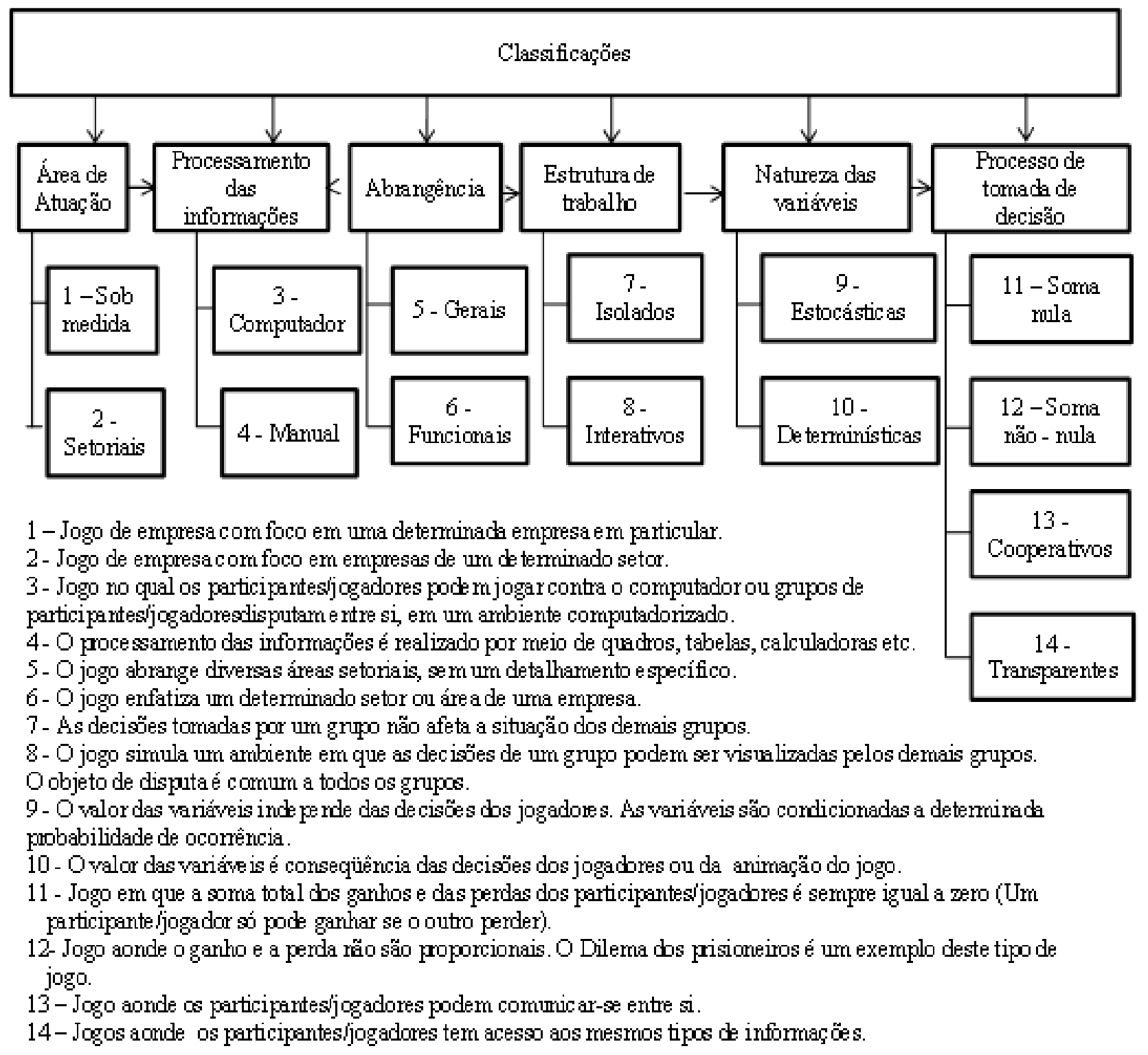

Figura 1 - Classificações e subclassificações para jogos de empresas. Fonte: Elaboração própria a partir de Destri Junior (1992) e Teixeira (2009)

\section{O Jogo do TECON}

O Jogo do TECON é um jogo de empresa que simula os processos de tomada de decisão inerentes ao planejamento operacional de terminais de contêineres. Foi elaborado por Silva (2010) no âmbito do projeto LABSIM (Laboratório de Simulação), realizado junto ao Programa de Pós-graduação em Engenharia de Transportes da Universidade Federal do Rio de Janeiro (UFRJ/COPPE/LTC), financiado pelo CNPq (Conselho Nacional de Desenvolvimento Científico e Tecnológico), visando a elaboração de 4 protótipos de jogos de empresas (aéreo, rodoviário, marítimo/portuário e logística), para auxiliar o processo de ensino-aprendizagem na área de transporte de carga. 
O Jogo do TECON pode ser classificado como um jogo que tem área de atuação setorial (porto - terminal de contêineres). Possui processamento computacional das informações, abrangência funcional (planejamento operacional), estrutura de trabalho interativa entre os componentes das equipes, variáveis de natureza determinísticas e estocásticas (módulos da equipe e instrutor respectivamente) e processo de tomada de decisão de soma não nula e transparente.

\subsection{Descrição do Jogo do TECON}

O problema a ser solucionado pelo participante do Jogo do TECON é praticar uma tarifa, dentro de um nível de serviço, que equilibre as entradas e saídas de recursos, de modo que a movimentação de contêineres seja viável em termos econômicos e operacionais. Para tanto, os participantes lidam com questões relativas ao desempenho operacional dos terminais de contêineres e a capacidade destes em oferecer as melhores tarifas, deslocando a demanda de contêineres por meio de variáveis como layout do terminal e perfil de operação (percentual de importação/exportação, tipos de contêineres movimentados, tipos de equipamentos) e investimentos em equipamentos.

O ambiente do jogo do TECON possui layouts de terminais de contêineres que foram modelados a partir de pesquisa documental realizada nos websites dos terminais de contêineres brasileiros e da Associação Brasileira de Terminais de Contêineres de Uso Público (ABRATEC), além de visitas técnicas aos terminais de contêineres das empresas MULTITERMINAIS e LIBRA T1, ambos localizados no Porto do Rio de Janeiro - Brasil.

O modelo dos processos de tomada de decisão simulado no jogo do TECON, assim como a base conceitual/teórica, foram desenvolvidos baseados em Cruz (1997), Fialho (1998), Ferreira (2001), Carvalho (2003), COPPEAD (2007), ABRATEC (2008), Goes Filho (2008), Bittencourt (2009) e ANTAQ (2009).

\subsection{Modelo conceitual do Jogo do TECON}

O cenário do jogo do TECON pressupõe que exista uma armadora denominada de LTC shipping que deseja realizar operações de importação, exportação e armazenagem de contêineres, cheios e vazios do tipo Standard de $20^{\prime}$ e 40', na zona portuária do Fundão (porto fictício).

A zona portuária do Fundão se localiza no estado do Rio de Janeiro e possui 4 (quatro) terminais de contêineres que podem realizar as operações demandadas pela LTC shipping. Para escolher qual(is) terminal(is) realizará(ão) as operações (importação, exportação e armazenagem) de forma a atender total ou parcialmente a demanda, a LTC shipping leva em consideração o indicador de atratividade dos terminais. A demanda é dividida de maneira diretamente proporcional ao indicador obtido pelo terminal. 
O indicador de atratividade do terminal está relacionado com os valores de indicadores de desempenho do terminal: 1) Quantidade de contêineres movimentados, 2 Preço médio de movimentação, 3) Tempo total de operação e 4) Prancha média. Os valores destas variáveis são dependentes de: 1) Layout dos terminais, 2) Tipos de investimentos realizados e 3) Objetivos operacionais/financeiros de cada equipe que participa do Jogo do TECON.

Para o cálculo do indicador, há um algoritmo no processador do jogo que realiza uma etapa de normalização, por meio de análise relacional grey (Bischof, 2008) e atribuiu pesos aos indicadores de desempenho do terminal com o intuito de gerar uma nota de 0 a 10 para cada terminal, conforme as equações 5.1, 5.2 e 5.3

O primeiro passo para se obter o indicador de atratividade de um terminal é realizar a normalização dos indicadores de desempenho do terminal de cada equipe/participante $\left(I_{i} E_{v}\right.$, onde $i=1 . . n$ ). Esta normalização dos indicadores de desempenho depende da forma como o indicador pode ser classificado:

Se o indicador for do tipo quanto maior melhor tem-se:

$$
\text { NIDiEV = IDiEV } / \text { Max (IDiEv) }
$$

Se o indicador for do tipo quanto menor melhor tem-se:

$$
\text { NIDiEV = Min (IDiEv)/IDiEV }
$$

Após realizar a normalização de todos os indicadores de desempenho do terminal pode-se, através da Equação 5.3, calcular o indicador de atratividade do terminal.

$$
\mathrm{IAE}_{\mathrm{v}}=\sum_{i=1}^{n} N I D_{i} E_{v} * P_{i}
$$

Onde:

NIDiEv = valor normalizado para 0 indicador de desempenho do tipo $\mathrm{i}$ da equipe/participante $\mathrm{v}$;

$I A E v=$ indicador de atratividade do terminal da equipe/participante $v$;

IDiEv $=$ valor do indicador de desempenho de tipo i da equipe/participante $v$, onde $i=1 . . n$

$\mathrm{Pi}$ = peso atribuído ao indicador de desempenho de tipo $\mathrm{i}$

O Quadro 2 apresenta a classificação dos indicadores de desempenho no Jogo do TECON e os respectivos pesos que cada um possui para a formação do indicador de atratividade 
Quadro 2 - Indicadores de desempenho no Jogo do TECON.

\begin{tabular}{l|c|c}
\multicolumn{1}{c|}{ Indicador } & Tipo do indicador para normalização & Peso \\
\hline $\begin{array}{l}\text { Quantidade de contêineres } \\
\text { movimentados }\end{array}$ & Quanto maior melhor & $\mathbf{3}$ \\
\hline Preço de movimentação & Quanto menor melhor & $\mathbf{3}$ \\
\hline Tempo de movimentação & Quanto menor melhor & $\mathbf{2 , 5}$ \\
\hline Prancha média & Quanto maior melhor & $\mathbf{1 , 5}$
\end{tabular}

Fonte: Elaboração própria.

\subsection{Estrutura do Jogo do TECON}

O Jogo do TECON foi elaborado para participação de quatro equipes e um instrutor. É composto por um manual de instruções que contém a descrição e as regras do jogo e dois módulos (softwares) de jogo: um módulo para as equipes e o outro para o instrutor, cujo desenvolvimento foi realizado por meio de programação VBA for EXCEL (Visual Basic for Application).

O Jogo do TECON é realizado em três rodadas que representam três meses de ciclos de planejamento operacional quando cada equipe poderá alterar sua estrutura de prestação de serviços, influenciando o nível de serviços, bem como os preços praticados.

Ao final de cada rodada, gera-se um arquivo no qual são registradas as decisões tomadas pela equipe, no módulo das equipes, e que será utilizado pelo instrutor, no módulo do instrutor, como base comparativa com as demais equipes, para obter o resultado da rodada. A equipe que tiver o melhor indicador de atratividade acumulado das três rodadas vence o jogo.

O módulo das equipes é exclusivo para as equipes e é o local onde serão registradas as decisões acerca do planejamento das operações simuladas de um terminal de contêineres, como também possibilita testar os resultados decorrentes das tomadas de decisão. Nesse módulo, temse acesso a um ambiente onde as variáveis assumem um comportamento determinístico e não sofrem influência das decisões tomadas pelas equipes concorrentes. O módulo do instrutor é exclusivo do responsável pela aplicação do Jogo do TECON, as variáveis que compõem seu ambiente assumem um comportamento probabilístico para torná-lo o mais próximo possível da realidade e este funciona como o processador do jogo.

O Jogo do TECON possui 5 macroprocessos de tomada de decisão: 1) Determinar área de armazenagem; 2) Arrendar um layout de terminal de contêiner; 3) Investir em equipamentos portuários, 4) Analisar a capacidade de atendimento e 5) Determinar preço de movimentação de contêiner.

Para auxiliar os processos de decisão (1) e (2), um histórico de demanda para as rodadas é disponibilizado, destacando: 1) Tipos de navios; 2) Tipos de contêineres e os 3) tipos de operação,

R. B. E. C. T., vol 7, núm. 1, jan-abr.2014 ISSN - 1982-873X

DOI: Em andamento. 
além de uma função matemática que calcula a necessidade de área para armazenar a demanda pretendida, com base nas características operacionais dos equipamentos portuários a serem adquiridos. Inicialmente, cada equipe possui uma determinada quantia (R\$) que deve ser usada para os processos de tomada de decisão (2) e (3).

Os layouts de terminal de contêineres possuem as seguintes informações: 1) Berço (quantidade, profundidade e extensão; 2) Dimensão das áreas (total, cais e físicas); 3) Valor de aquisição e das taxas de arrendamento [em função do uso da área $\left(\mathrm{R} \$ \mathrm{~m}^{2}\right)$ e da quantidade de contêineres movimentados $(\mathrm{R} \$ / \mathrm{co})]$. Cada layout de terminal de contêineres possui uma capacidade de movimentação de contêineres para exportação por rodada. A ausência de interface com os modos terrestres e de realização de operação de cabotagem foram simplificações da realidade adotadas no Jogo do TECON.

Para auxiliar o processo de decisão (3), o jogo disponibiliza configurações compostas por conjuntos de equipamentos de cais e de pátio, com as seguintes informações: 1) Operacionais (capacidade, produtividade, altura de empilhamento e número de filas permitidos) e 2) Financeiras (valor de aquisição e custos da configuração: manutenção, operação e mão de obra).

O jogo permite ainda que seja realizada a simulação da capacidade de atendimento do terminal, apoiando o macro processo (4). Para tanto, são considerados a demanda pretendida, o layout de terminal arrendado e a configuração de equipamentos adquirida, calculando todos os custos do terminal e informando o custo referente à movimentação de 1 contêiner. Caso necessário, é possível realizar alterações na demanda pretendida, ou ainda investir em equipamentos adicionais para a configuração, com o intuito de atender a demanda e ou ampliar a produtividade do terminal.

A simulação da capacidade auxilia, ainda, o processo de decisão (5). Para todos os layouts de terminal de contêineres o valor de movimentação do contêiner vazio apresenta um desconto de $15 \%$ em função do valor de movimentação do cheio. Deve-se ainda levar em consideração o lucro que se deseja alcançar e o impacto que a combinação dos macroprocessos de tomada de decisão (2), (3) e (4) causam no indicador de atratividade do terminal.

\subsection{Ementa dos cursos de formação na área de portos no Brasil e o Jogo do TECON}

Para demonstrar a adequação do Jogo do TECON às ementas dos cursos Técnicos em Portos e Tecnológicos em Gestão Portuária no Brasil os itens que compõem suas ementas foram confrontados com os elementos que envolvem os processos de tomada de decisão relacionados com o planejamento operacional e a gestão de terminais portuários presentes no Jogo do TECON.

O Quadro 3 consolida o resultado dessa etapa do presente trabalho e evidencia a relação entre as ementas de cursos Técnicos em Portos e Tecnológicos em Gestão Portuária e a base conceitual que compõe o Jogo do TECON.

90 DOI: Em andamento.

R. Bras. de Ensino de C\&T 
Quadro 3 - Relação entre as ementas de cursos técnicos em portos e tecnológicos em gestão portuária e a base conceitual do Jogo do TECON.

\begin{tabular}{|c|c|c|c|c|}
\hline \multirow{2}{*}{ Curso } & \multirow{2}{*}{$\begin{array}{l}\text { Grupo de } \\
\text { disciplinas }\end{array}$} & \multirow{2}{*}{ Resumo das ementas } & \multicolumn{2}{|r|}{ TECON } \\
\hline & & & Considera? & Como? ${ }^{2}$ \\
\hline \multirow{4}{*}{$\begin{array}{c}\text { Técnico em } \\
\text { portos }\end{array}$} & \multirow{4}{*}{$\begin{array}{l}\text { Operações } \\
\text { portuárias }^{1}\end{array}$} & $\begin{array}{l}\text { Conceito de operações } \\
\text { portuárias }\end{array}$ & Sim & $\begin{array}{l}\text { Movimentação de contêineres } \\
\text { (carga, descarga e armazenagem) }\end{array}$ \\
\hline & & Tipos de cargas & Sim & $\begin{array}{l}\text { Carga contêinerizada por tipo e } \\
\text { estado (cheio/vazio) }\end{array}$ \\
\hline & & Tipos de navio & Sim & $\begin{array}{l}4 \text { gerações de navio (tipo, calado } \\
\text { capacidade e comprimento) }\end{array}$ \\
\hline & & $\begin{array}{l}\text { Serviços dos terminais } \\
\text { portuários (imp. e exp.) }\end{array}$ & Sim & $\begin{array}{l}\text { Operação de contêineres para } \\
\text { importação e para exportação }\end{array}$ \\
\hline \multirow{10}{*}{$\begin{array}{l}\text { Tecnológico } \\
\text { em Gestão } \\
\text { Portuária }\end{array}$} & \multirow{6}{*}{$\begin{array}{l}\text { Gestão de } \\
\text { armazéns }\end{array}$} & Objetivos dos armazéns & $\operatorname{Sim}$ & \multirow{2}{*}{$\begin{array}{l}\text { Área necessária para movimentar a } \\
\text { demanda pretendida }\end{array}$} \\
\hline & & Dimensionamento & Sim & \\
\hline & & Layout & Sim & $\begin{array}{l}4 \text { tipos de layout de terminais } \\
\text { disponíveis para arrendamento }\end{array}$ \\
\hline & & Equipamentos portuários & Sim & $\begin{array}{l}\text { Equipamentos de cais e pátio, e } 3 \\
\text { pré-configurações de terminais }\end{array}$ \\
\hline & & Recursos humanos & Sim & $\begin{array}{l}\text { Relação de mão-de-obra por tipo } \\
\text { de equipamento portuário }\end{array}$ \\
\hline & & Custos & Sim & $\begin{array}{l}\text { Custo total do terminal e custo } \\
\text { para movimentar } 1 \text { contêiner }\end{array}$ \\
\hline & \multirow{4}{*}{$\begin{array}{l}\text { Gestão } \\
\text { portuária }\end{array}$} & Sistema Portuário & Não & - \\
\hline & & Legislação aduaneira & Não & - \\
\hline & & Modelos de gestão & Não & - \\
\hline & & Logística internacional & Não & - \\
\hline
\end{tabular}

Notas: ${ }^{1}$ Compõe também a matriz curricular dos cursos tecnológicos em gestão portuária. ${ }^{2} \mathrm{~A}$ consideração dos itens da ementa dos cursos se dá de forma parcial.

Fonte: Silva (2010). 
Verifica-se que o Jogo do TECON atende a todos os aspectos operacionais apresentados nas ementas dos cursos de Técnico em Portos e de Tecnólogo em Gestão Portuária. Destaca-se que a parte deste segundo curso não contemplada no Jogo do TECON não faz parte das atividades operacionais: Sistema Portuário, Legislação Aduaneira, Modelos de Gestão e Logística Internacional.

\subsection{O Ciclo de aprendizagem vivencial e o Jogo do TECON}

O processo de aplicação do Jogo do TECON pode ser sintetizado em 3 macro etapas: 1) Preparatória; 2) Ciclo repetitivo e 3) Encerramento (Silva, 2010).

A primeira macro etapa é o momento no qual há a preparação das equipes para o jogo: o instrutor atua como o principal elemento e é responsável por apresentar o cenário simulado, as regras do Jogo do TECON e esclarecer as dúvidas das equipes, caso existam.

No ciclo repetitivo, segunda macro etapa da aplicação, há uma sequência de ações (processos de tomada de decisão) que ocorrem durante o jogo e se repetem após o início de todas as rodadas. Neste ciclo, diferentemente da fase preparatória, ocorre alternância de atuação entre o momento de participação das equipes (planejamento e tomada das decisões) e o momento de participação do instrutor (processamento das decisões).

A terceira e última macro etapa é o encerramento do jogo que, assim como a fase de preparação, ocorre uma única vez. Neste momento, são apresentados os resultados obtidos ao longo de todas as rodadas e as equipes, juntamente com o instrutor, realizam um debate para comparação e reflexão a respeito das decisões tomadas por cada equipe e os respectivos resultados.

É possível associar o C.A.V. com as macro etapas de aplicação do Jogo do TECON. Ao atender os pressupostos da aprendizagem vivencial o Jogo do TECON apresenta-se como uma alternativa para formação profissional na área de portos. A interação de cada fase do C.A.V. com o Jogo do TECON são apresentadas no Quadro 4. 
Quadro 4 - Adequação do Jogo do TECON ao Ciclo de Aprendizagem

Vivencial.

\begin{tabular}{|c|c|c|c|}
\hline \multirow{3}{*}{$\begin{array}{c}\text { Fases do C.A.V. } \\
\\
\text { Experiência } \\
\text { Concreta }\end{array}$} & & & \multirow{3}{*}{$\begin{array}{l}\text { Adequação do Jogo do TECON ao } \\
\text { C.A.V } \\
\text { Nesta etapa, o participante } \\
\text { concretiza a experiência de } \\
\text { participar de um jogo a partir da } \\
\text { contextualização do ambiente } \\
\text { simulado e do acesso às decisões } \\
\text { que deverão ser tomadas ao longo } \\
\text { das rodadas. }\end{array}$} \\
\hline & \multicolumn{2}{|c|}{ Etapas de aplicação do Jogo do TECON } & \\
\hline & Preparatória & $\begin{array}{l}\text { 1) Contextualização do } \\
\text { ambiente simulado } \\
\text { 2) Divisão dos alunos } \\
\text { 3) Apresentação das } \\
\text { regras }\end{array}$ & \\
\hline $\begin{array}{l}\text { Observação } \\
\text { Reflexiva }\end{array}$ & \multirow{2}{*}{$\begin{array}{l}\text { Ciclo } \\
\text { epetitivo }\end{array}$} & \multirow{2}{*}{$\begin{array}{l}\text { 1) Planejamento para a } \\
\text { tomada de decisão } \\
\text { 2) Revelação das decisões } \\
\text { tomadas para o instrutor } \\
\text { 3) Processamento das } \\
\text { tomadas de decisão } \\
\text { 4) Geração de relatórios } \\
\text { com os resultados } \\
\text { obtidos por cada equipe }\end{array}$} & $\begin{array}{l}\text { Nesta etapa, o participante } \\
\text { observa e analisa o cenário do } \\
\text { jogo e a partir de reflexões, com } \\
\text { base em seus conhecimentos } \\
\text { concretos, toma decisões com o } \\
\text { intuito de ganhar o jogo. }\end{array}$ \\
\hline $\begin{array}{c}\text { Conceituação } \\
\text { Abstrata }\end{array}$ & & & $\begin{array}{l}\text { Nesta etapa, o participante, a } \\
\text { partir dos resultados de suas } \\
\text { tomadas de decisão, reforça o } \\
\text { conhecimento pré-existente ao } \\
\text { mesmo tempo em que desenvolve } \\
\text { novos conhecimentos por meio } \\
\text { das tomadas de decisão. }\end{array}$ \\
\hline $\begin{array}{c}\text { Experimentação } \\
\text { Ativa }\end{array}$ & Encerramento & $\begin{array}{l}\text { 1) Apresentação da } \\
\text { equipe vencedora de } \\
\text { acordo com as regras } \\
\text { estabelecidas na fase } \\
\text { preparatória } \\
\text { 2) Discussão e análise dos } \\
\text { resultados obtidos pelas } \\
\text { equipes }\end{array}$ & $\begin{array}{l}\text { Nesta etapa, o participante recebe } \\
\text { o feedback do instrutor e busca, } \\
\text { em função de seu resultado, } \\
\text { identificar as decisões corretas e } \\
\text { incorretas, consolidando seus } \\
\text { conhecimentos após a } \\
\text { participação no jogo. }\end{array}$ \\
\hline
\end{tabular}

Fonte: Elaboração própria. 


\section{Aplicação do Jogo do TECON no curso de Técnico em Portos}

Com o intuito de testar a adequação do Jogo do TECON como ferramenta de apoio educacional, realizou-se uma aplicação experimental do jogo no curso Técnico em Portos do CEFET/Itaguaí. Este centro de formação foi selecionado por ser uma instituição de ensino de nível técnico que oferece o curso de Técnico em Portos, é localizado na região Sudeste facilitando o acesso para realização da aplicação do jogo e, principalmente, porque houve o interesse por parte de alguns dos professores do curso em usar esse ferramenta junto aos alunos do curso.

O objetivo foi demonstrar a aplicabilidade do Jogo do TECON no que diz respeito ao auxílio no desenvolvimento do conhecimento, uma vez que objetivo do Jogo do TECON é apoiar o processo de ensino-aprendizagem, ao exigir que os alunos apliquem conhecimentos já explorados em um ambiente simulado.

A aplicação seguiu as três macro etapas do Jogo do TECON:

1) Preparatória: Na fase preparatória os objetivos, as regras e a estrutura do Jogo do TECON foram apresentados. Os 20 alunos da turma do curso Técnico em Portos do CEFET/Itaguaí, que cursam no 4 o período a disciplina Operação de Contêiner, foram divididos em quatro equipes.

2) Ciclo Repetitivo: $O$ ciclo repetitivo foi composto por 3 rodadas com duração de 30 minutos cada. Cada rodada representava 1 mês de operação do terminal. Ao término das rodadas as equipes eram pontuadas, de 0 a 10, em virtude dos resultados operacionais e financeiros alcançados pelo seu layout de terminal de contêiner.

3) Encerramento: Na fase de encerramento foram apresentados os resultados e houve uma discussão dirigida pela instrutora com a finalidade de esclarecer dúvidas e justificar resultados. Venceu o jogo a equipe que obteve o maior indicador de atratividade a partir do somatório dos indicadores de atratividade obtidos nas 3 rodadas.

Ao final da aplicação do Jogo do TECON, para verificar sua consistência e aderência ao conteúdo da disciplina Operação de Contêiner do curso Técnico de Portos, os alunos e o professor da disciplina foram submetidos a um questionário acerca das decisões tomadas durante o ciclo repetitivo. As questões tratavam das 33 variáveis relacionadas aos 5 macroprocessos de tomada de decisão, tal como apresentado no Quadro 5. 
Quadro 5 - Variáveis que compõem os processos de tomada de decisão do Jogo do TECON.

\begin{tabular}{|c|c|c|}
\hline & $\begin{array}{l}\text { cessos de tomada de } \\
\text { decisão }\end{array}$ & Variáveis que deveriam ter sido consideradas na tomada de decisão \\
\hline 1 & \multirow{4}{*}{$\begin{array}{l}\text { Determinar área de } \\
\text { armazenagem }\end{array}$} & Demanda de contêineres por tipo \\
\hline 2 & & Altura de empilhamento do equipamento portuário \\
\hline 3 & & Área bruta \\
\hline 4 & & Área líquida \\
\hline 5 & \multirow{6}{*}{$\begin{array}{l}\text { Investir em layout de } \\
\text { terminal }\end{array}$} & Quantidade de berços \\
\hline 6 & & Profundidade dos berços \\
\hline 7 & & Extensão dos berços \\
\hline 8 & & Área total do terminal (cais + físicas) \\
\hline 9 & & Valor do arrendamento \\
\hline 10 & & Capacidade de movimentação de contêineres \\
\hline 11 & \multirow{8}{*}{$\begin{array}{l}\text { Investir na } \\
\text { configuração de } \\
\text { equipamentos }\end{array}$} & Valor de aquisição \\
\hline 12 & & Características operacionais \\
\hline 13 & & Capacidade média \\
\hline 14 & & Produtividade \\
\hline 15 & & Vida útil \\
\hline 16 & & Custo de manutenção \\
\hline 17 & & Custo de operação \\
\hline 18 & & Custo de mão de obra \\
\hline 19 & \multirow{7}{*}{$\begin{array}{l}\text { Analisar capacidade de } \\
\qquad \text { atendimento }\end{array}$} & Taxa média de chegada de navios \\
\hline 20 & & Tempo médio de atendimento \\
\hline 21 & & Taxa de ocupação do terminal \\
\hline 22 & & Taxa de possibilidade de crescimento \\
\hline 23 & & Quantidade de navios atendidos em função da demanda prevista \\
\hline 24 & & Quantidade de navios não atendidos em função da demanda prevista \\
\hline 25 & & Quantidade de contêineres movimentados \\
\hline
\end{tabular}

R. B. E. C. T., vol 7, núm. 1, jan-abr.2014 ISSN - 1982-873X

DOI: Em andamento. 


\section{Continuação do Quadro 5}

\begin{tabular}{|c|c|c|}
\hline \multicolumn{2}{|c|}{$\begin{array}{l}\text { Processos de tomada de } \\
\text { decisão }\end{array}$} & Variáveis que deveriam ter sido consideradas na tomada de decisão \\
\hline 26 & \multirow{8}{*}{$\begin{array}{l}\text { Determinar preço de } \\
\text { movimentação }\end{array}$} & Custo com a taxa de arrendamento $\left(\mathrm{R} \$ / \mathrm{m}^{2}\right)$ \\
\hline 27 & & Custo com a taxa de arrendamento ( $\mathrm{R} \$ \mathrm{co})$ \\
\hline 28 & & Custo de manutenção \\
\hline 29 & & Custo de operação \\
\hline 30 & & Custo de mão de obra \\
\hline 31 & & Custo total por contêiner \\
\hline 32 & & Lucro pretendido \\
\hline 33 & & Indicador de atratividades \\
\hline
\end{tabular}

Além de o aluno ter que indicar quais das variáveis foram consideradas nas decisões relacionadas a cada um dessas áreas, era necessário que fosse atribuído o nível de importância em uma escala Tipo Likert de 1 (menos importante) a 5 (mais importante) para as mesmas. Se uma variável não foi considerada na tomada de decisão bastava deixar o conceito em branco. 0 objetivo foi apurar em que medida o aluno considerava que cada variável influenciava no resultado da decisão.

O resultado do questionário do professor representou a opinião de um especialista para verificar o quanto as variáveis identificadas eram importantes para o processo de decisão. Assim, os valores atribuídos pelo professor foram tratados como gabarito para as respostas dos alunos. A análise dos resultados foi realizada considerando o quanto os alunos se aproximaram/distanciaram das respostas do professor e qual foi a relação entre suas opções e sua colocação ao final do Jogo do TECON.

\section{Resultados e discussão}

O objetivo da entrevista junto aos alunos foi o de verificar quais das variáveis apresentadas na Tabela 5, foram consideradas nas tomadas de decisão, bem como o grau de importância considerado (5 para muito importante, 4 para importante, 3 para média importância, 2 para pouco importante e 1 para muito pouco importante). Caso a variável não tivesse sido considerada o aluno não deveria atribuir conceito à mesma.

O conceito atribuído a cada variável pelo aluno foi comparado ao atribuído pelo professor a 
essa mesma variável. Após a verificação da frequência com que foram obtidas respostas com grau de importância igual ou maior ou menor ao do professor foi elaborado o Quadro 6.

Quadro 6 - Frequência de ocorrência das variáveis com grau de importância igual, maior ou menor que o valor atribuído pelo professor.

\begin{tabular}{|c|c|c|c|c|c|c|c|c|c|c|c|c|}
\hline \multirow{3}{*}{$\begin{array}{c}\text { Macro processos } \\
\text { de tomada de } \\
\text { decisão }\end{array}$} & \multicolumn{12}{|c|}{$\begin{array}{l}\text { Frequência de ocorrências de variáveis com importância igual, maior e menor } \\
\text { atribuída pelas equipes participantes do Jogo do TECON em relação ao valor } \\
\text { atribuído pelo professor. }\end{array}$} \\
\hline & \multicolumn{3}{|c|}{ Equipe 4} & \multicolumn{3}{|c|}{ Equipe 2} & \multicolumn{3}{|c|}{ Equipe 1} & \multicolumn{3}{|c|}{ Equipe 3} \\
\hline & $\begin{array}{l}\bar{\pi} \\
\underline{\underline{b}}\end{array}$ & $\stackrel{\frac{.}{0}}{\frac{0}{\pi}}$ & 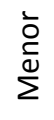 & $\begin{array}{l}\bar{\pi} \\
\overline{\underline{0}}\end{array}$ & $\sum_{\substack{\frac{0}{\pi} \\
\Sigma}}^{\frac{1}{\pi}}$ & 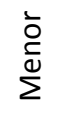 & $\begin{array}{l}\overline{\frac{\pi}{2}} \\
\underline{\underline{\sigma}}\end{array}$ & $\frac{. \overline{0}}{\frac{0}{\pi}}$ & 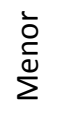 & $\begin{array}{l}\bar{\pi} \\
\underline{\underline{\sigma}}\end{array}$ & $\frac{. \overline{0}}{\sum^{\pi}}$ & 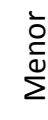 \\
\hline $\begin{array}{l}\text { Determinar área de } \\
\text { armazenagem }\end{array}$ & 0 & 4 & 0 & 0 & 4 & 0 & 0 & 4 & 0 & 0 & 3 & 1 \\
\hline $\begin{array}{l}\text { Investir em layout } \\
\text { de terminal }\end{array}$ & 3 & 4 & 1 & 3 & 3 & 0 & 4 & 2 & 0 & 1 & 1 & 4 \\
\hline $\begin{array}{l}\text { Investir na } \\
\text { configuração de } \\
\text { equipamentos }\end{array}$ & 6 & 3 & 2 & 0 & 8 & 0 & 2 & 6 & 0 & 1 & 5 & 2 \\
\hline $\begin{array}{l}\text { Analisar capacidade } \\
\text { de atendimento }\end{array}$ & 1 & 2 & 3 & 1 & 6 & 0 & 0 & 4 & 3 & 1 & 5 & 1 \\
\hline $\begin{array}{l}\text { Determinar preço de } \\
\text { movimentação }\end{array}$ & 4 & 4 & 3 & 4 & 4 & 0 & 1 & 1 & 6 & 4 & 1 & 3 \\
\hline Total & 14 & 13 & 9 & 8 & 25 & 0 & 7 & 17 & 9 & 7 & 15 & 11 \\
\hline
\end{tabular}

Fonte: Elaboração própria.

Verifica-se que a Equipe 4 atribuiu importância equivalente à apontada pelo professor da disciplina no maior número de variáveis quando comparado com os resultados das demais equipes. $O$ número de variáveis cujo conceito foi igual ao do professor por equipe é: Equipe $4 \mathrm{com}$ 14 variáveis; Equipe 2 com 8 variáveis; Equipe 1 com 7 variáveis e Equipe 3 com 7 variáveis.

Por outro lado, verifica-se que a Equipe 3 atribuiu importância relativamente menor ao apontado pelo professor da disciplina no maior número de variáveis quando comparado com os resultados das demais equipes. O número de variáveis cujo conceito foi inferior ao do professor 
por equipe é: Equipe 3 com 11 variáveis; Equipes 1 e 4 com 9 variáveis cada e Equipe 2 com nenhuma variável com conceito inferior ao do professor.

Ao confrontar o resultado das entrevistas com os alunos com a do professor, e também com o resultado obtido pelas equipes no Jogo do TECON, verifica-se que a equipe que atribuiu importância equivalente à apontada pelo professor no maior número de variáveis é a mesma que ficou classificada em primeiro lugar. Destaca-se, ainda, que há uma relação direta entre a colocação de cada equipe na aplicação experimental do Jogo do TECON com o número de variáveis com importância igual à determinada pelo professor da disciplina.

Ao confrontar as respostas que foram diferentes das apontadas pelo professor verificam-se duas situações: 1) Em sua maioria, os alunos atribuíram maior importância às variáveis na tomada de decisão em relação ao conceito apresentado pelo professor; 2) A equipe que apresentou o maior número de variáveis com importância inferior ao conceito do professor foi aquela que ficou em último lugar na aplicação experimental do Jogo do TECON.

No âmbito desse trabalho não há elementos suficientes para afirmações conclusivas visto que se trata de uma aplicação experimental, para uma única turma, tomando como base o conceito apontado por um especialista (o professor). Entretanto, é possível afirmar, nesse caso, que há a relação entre o desempenho das equipes no Jogo do TECON (uma prática vivencial) e o nível de importância dado por essas equipes para sua tomada de decisão (uma abordagem conceitual).

A relação entre o resultado do jogo e o número de resposta cuja importância atribuída pelos alunos foi igual ou menor que a atribuída pelo professor é apresentada no Quadro 7.

\begin{tabular}{c|c|c|c} 
Quadro 7 - Resultado das equipes que participaram do Jogo do TECON. \\
Equipe & $\begin{array}{c}\text { Colocação no } \\
\text { Jogo do TECON }\end{array}$ & $\begin{array}{c}\text { № de variáveis com grau de } \\
\text { importância igual ao do } \\
\text { professor }\end{array}$ & $\begin{array}{c}\text { № de variáveis com grau de } \\
\text { importância menor que o do } \\
\text { professor }\end{array}$ \\
\hline Equipe 4 & 10 lugar & 14 & 9 \\
\hline Equipe 2 & 2o lugar & 8 & 0 \\
\hline Equipe 1 & 3o lugar & 7 & 9 \\
\hline Equipe 3 & 4o lugar & 7 & 11
\end{tabular}

Fonte: Elaboração própria.

A forma como se apresentam os resultados obtidos não permite fazer afirmações acerca da relação entre o resultado do jogo e as respostas nas quais os alunos atribuíram maior importância 
às variáveis na tomada de decisão em relação à atribuída pelo professor.

A Figura 2 consolida as respostas de todos os alunos que participaram da aplicação experimental do Jogo do TECON frente àquela atribuída pelo professor. Assim, é possível comparar em quais e em que magnitude o conjunto de alunos divergiu da proposição do professor.

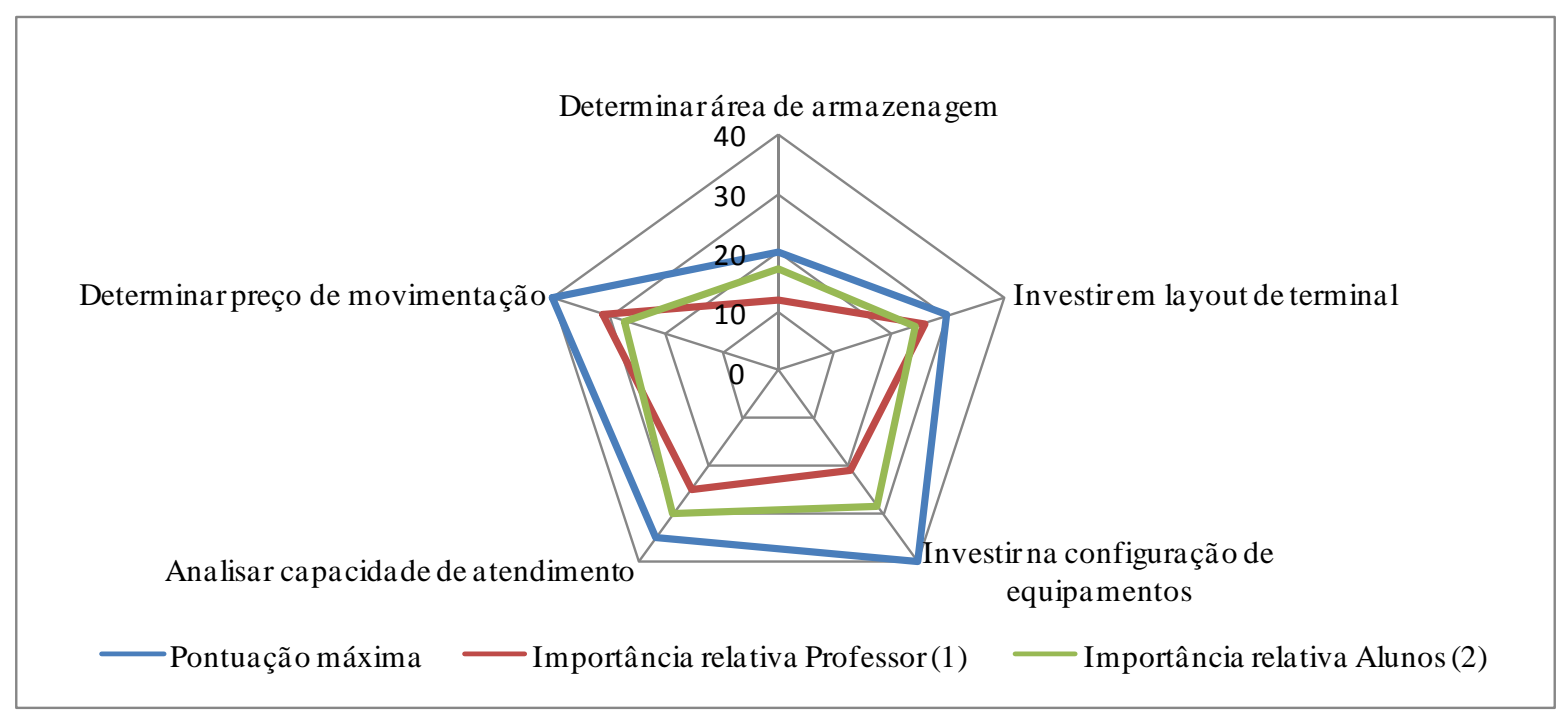

Figura 2 - Consolidação das importâncias dadas as variáveis: alunos $x$ professor.

Fonte: Elaboração própria.

Verifica-se que em três dos macroprocessos de tomada de decisão os alunos atribuíram importância maior ao conjunto de variáveis relacionado que o atribuído pelo professor: 1) Determinar a área de armazenagem; 2) Investir na configuração de equipamentos e 3) Analisar a capacidade de atendimento. O processo Investir em layout de terminal teve conceito praticamente igual entre professor e alunos enquanto que o processo Determinar preço de movimentação teve sua importância reconhecida mais fortemente pelo professor que pelos alunos.

Desta forma, é possível identificar outra contribuição decorrente do uso do Jogo do TECON: o professor poderá, a partir desses resultados, verificar se a abordagem conceitual para dar suporte a problemas correlatos ao proposto pelo Jogo do TECON - praticar uma tarifa, dentro de um nível de serviço, que equilibre as entradas e saídas de recursos de modo que a movimentação de contêineres seja viável em termos econômicos e operacionais - está sendo ministrado de forma adequada (conteúdo, didática, estratégias, avaliações etc.). Em paralelo, uma reavaliação dos pesos atribuídos às variáveis utilizadas, ou ainda, se a relação de variáveis é suficiente, poderiam ser iniciativas para identificar oportunidades de melhoria no processo de avaliação do uso do Jogo do TECON.

R. B. E. C. T., vol 7, núm. 1, jan-abr.2014 ISSN - 1982-873X

DOI: Em andamento. 


\section{Conclusões}

O presente trabalho atingiu seu objetivo ao demonstrar que o jogo de empresa - Jogo do TECON - é adequado para apoiar o processo de ensino-aprendizagem na área de planejamento operacional de terminais de contêineres.

Para tanto, ao longo do trabalho foi possível verificar que o Jogo do TECON representa uma ferramenta de apoio ao processo de ensino-aprendizagem, inovadora, que atende aos pressupostos do ciclo de aprendizagem vivencial, e que facilitou a associação entre a teoria e a prática por meio de um ambiente simulado.

A aproximação entre a teoria e a prática foi evidenciada durante o processo de análise dos resultados da aplicação do Jogo do TECON para a turma de $4^{\circ}$ período do curso técnico em portos do CEFET/Itaguaí, visto que a equipe que venceu o jogo (prática) foi a que considerou os níveis de importância das variáveis que compõem os processos de tomada de decisão do Jogo do TECON mais próximos aos apontados pelo professor (teoria).

A forma de avaliação do resultado do Jogo do TECON não permitiu gerar, em virtude da realização de apenas uma aplicação do jogo, elementos suficientes para afirmar que o aluno (equipe) que fez as escolhas mais próximas do professor e, ao mesmo tempo obteve as melhores colocações, tenha aprendido e assimilado melhor o conteúdo abordado no jogo.

Para trabalhos futuros sugere-se que seja realizado um número maior de aplicações do jogo, não só com a turma do $4^{\circ}$ período, mas também do $3^{\circ}$ período, para que seja criado um grupo de controle e seja possível verificar se é necessário que o participante tenha conhecimento prévio do conteúdo e o quanto o método utilizado pelo professor para transmitir esse conteúdo pode influenciar no resultado do jogo.

Além disso, é necessário aplicar o questionário para um número maior de especialistas com o intuito de gerar um gabarito para o jogo e determinar, na média, o grau de importância que cada variável realmente deve ter no processo de tomada de decisão, minimizando assim a influencia que a aplicação apresentada neste trabalho teve dos pesos considerados pelo professor.

\section{Referências}

AGÊNCIA NACIONAL DE TRANSPORTES AQUAVIÁRIOS - ANTAQ. Panorama Aquaviário. Disponível em: <http://www.antaq.gov.br/Portal/Pdf/PanoramaAquaviario4.pdf>. Acesso em: 03/07/2009 ASSOCIAÇÃO BRASILEIRA DOS TERMINAIS DE CONTÊINERES DE USO PÚBLICO - ABRATEC. Terminais de contêineres - Desempenho 2008. Disponível em <http://www.abratecterminais.org.br> Acesso em 29/03/2008. 
BISCHOFF, E. Estudo da utilização de algoritmos genéticos para seleção de redes de acesso. Dissertação de mestrado em engenharia elétrica, Departamento de Engenharia Elétrica. Universidade de Brasília, Brasília, DF. 2008.

BITTENCOURT, P. Informações à respeito do terminal de contêineres LIBRA - T1- Porto do Rio de Janeiro. Comunicação pessoal com o diretor da LIBRA - T1. Rio de Janeiro - RJ. 2009.

CARVALHO, A. C. P. DE. Uma Contribuição ao Estudo do Desempenho de Terminais de contêineres. Dissertação de mestrado. Programa de Engenharia de Transportes, Universidade Federal do Rio de Janeiro, COPPE, UFRJ. 2003

\section{CATÁLOGO NACIONAL DE CURSOS SUPERIORES DE TECNOLOGIA - CNCST . Ministério da}

Educação. Disponível em: < http://catalogo.mec.gov.br/anexos/catalogo_completo.pdf>. 2006. Acesso em: 04/07/2010.

CATÁLOGO NACIONAL DE CURSOS TÉCNICOS - CNCT . Ministério da Educação. Disponível em: < http://catalogonct.mec.gov.br/>. 2008. Acesso em: 03/07/2010.

CENTRO FEDERAL DE EDUCAÇÃO TECNOLÓGICA CELSO SUCKOW DA FONSECA - CEFET . Matriz Curricular do Curso Técnico em Portos. Campus Itaguaí, Rio de Janeiro, Brasil. 2012.

CENTRO UNIVERSITÁRIO MONTE SERRAT - UNIMONTE. Matriz Curricular do Curso Gradus Unimonte em Gestão Portuária. Disponível em: < http://www.unimonte.br/curso/gradusunimonte/gestao-portuaria/grade $>$. Acesso em: 05/07/2012.

CENTRO UNIVERSITÁRIO VILA VELHA - UVV . Matriz Curricular do Curso Superior de Tecnologia em Gestão Portuária. Disponível em: < http://www.uvv.br/ensino/info_curso.aspx?id=220 >. Acesso em: 04/07/2012.

COPPEAD . Análise e avaliação dos portos brasileiros. Relatório de pesquisa - Panorama logístico. Centro de estudos em logística, CEL/COPPEAD. 2007.

CRUZ, M. M. DA. C. Uma contribuição ao estudo da dinâmica de sistemas de terminais especializados de contêineres sob o enfoque sistêmico. Tese de doutorado. Programa de engenharia de transportes, COPPE, UFRJ. 1997.

DESTRI JUNIOR, J. Simulação empresarial em empresas de transporte rodoviário de cargas.

Dissertação de mestrado. Departamento de engenharia de produção. Universidade Federal de Santa

Catarina - UFSC, Florianópolis. 1992.

FACULDADE METROPOLITANA DA GRANDE RECIFE - UNESJ. Grade Curricular do curso superior de Tecnologia em Gestão Portuária. Disponível em:

<http://portal.metropolitana.edu.br/Academico/Integracao/Grade/ListaGrade.aspx?curso=GPO>. Acesso em: 05/07/2012.

R. B. E. C. T., vol 7, núm. 1, jan-abr.2014 ISSN - 1982-873X

DOI: Em andamento. 
FERREIRA, R. Equipamentos portuários para movimentação de cargas: Operações com contêineres. Curso especial em gerenciamento de portos. Módulo VI: Gestão de empreendimentos portuários. COPPE/UFRJ. 2001.

FIALHO, G.O.M.Módulo V: Planejamento Portuário Gestão portuária. Curso especial em gestão portuária. CIAGA. Rio de Janeiro - RJ. 1998.

GOES FILHO, H. DE. A. Notas de aula da disciplina Planejamento portuário. Curso de pósgraduação em engenharia portuária. Escola politécnica de engenharia, UFRJ. 2008.

HOFESTEDE, G. J. E CALUWÉ, L. D., PETERS, V. Synthesis Why Simulation Games Work-In Search of the Active Substance: A Synthesis. Simulation Gaming 2010 41: 824 originally published online 5 August 2010. DOI: 10.1177/1046878110375596.

INSTITUTO FEDERAL DO ESPÍRITO SANTO - IFES. Matriz Curricular do Curso Técnico em Portos. Disponível em:<http://www.cefetes.br/internet_arquivos/Ensino/Tecnico/Unidade_cariacica/ Portos/matriz\%20curso\%20em\%20portos.pdf>. Acesso em: 05/07/2012.

INSTITUTO FEDERAL DO MARANHÃO - IFMA. Matriz Curricular do Curso Técnico em Portos. Campus Monte Castelo, São Luíz, Maranhão, Brasil. 2012.

KOLB, D. A. Experiential learning: experience as a source of learning and development.New Jersey (EUA): Prentice-Hall. 1994.

LEWIS, M. A., MAYLOR, H. R. Game playing and operations management education. Int. J. Production Economics 105 (2007) 134-149. Disponível em www.elsevier.com/locate/ijpe. doi:10.1016/j.ijpe.2006.02.009

MINISTÉRIO DA EDUCAÇÃO - MEC. Sistema Nacional de Informações da Educação Profissional e Tecnológica. Disponível em: < http://sistec.mec.gov.br/consultapublicaunidadeensino>. Acesso em: 05/07/2012.

MINISTÉRIO DOS TRANSPORTES - MT. Boletim Informativo Portuário. Brasília: Superintendência de Portos. Gerência de Estudos e Desempenho Portuário. 1ำ Trimestre/2012.

SAUAIA, A. C. A. Laboratório de Gestão: Simulador, Jogo de Empresas e Pesquisa Aplicada. Barueri, SP: Manole. 2008.

SERVIÇO NACIONAL DE APRENDIZAGEM INDUSTRIAL DE SANTA CATARINA - SENAI/SC . Conteúdo Programático do Curso Técnico em Portos. Disponível

em:<http://www.sc.senai.br/siteinstitucional/

servicos/curso/show/curso/94039>. Acesso em: 05/07/2010.

SILVA, E. L DA E MENEZES, E. M. Metodologia da pesquisa e elaboração de dissertação. 3a ed. UFSC/PPGEP/LED, Florianópolis. 2001. 
SILVA, S.D .A utilização de jogos de empresa como ferramenta de ensino para formação profissional em terminais de contêineres. Dissertação de Mestrado. Programa de Engenharia de Transportes - PET/COPPE/UFRJ. Universidade Federal do Rio de Janeiro. Rio de Janeiro, Brasil. 2010.

TANABE, M. Jogos de empresas. Dissertação de mestrado. São Paulo: Faculdade de Econômica e Administração. Universidade de São Paulo. 1977.

TEIXEIRA. I .Estratégia Aplicada - Teoria dos Jogos. Apostila texto com o conteúdo de aula. 2009. UNIVERSIDADE CATÓLICA DE SANTOS - UNISANTOS. Currículo do Curso Tecnológico em Gestão Portuária. Disponível em: < http://www.unisantos.br>. Acesso em: 05/07/2012.

UNIVERSIDADE DO VALE DO ITAJAÍ - UNIVALI. Matriz Curricular do Curso de Tecnologia em Gestão Portuária. Disponível em:<http://www.univali.br/>. Acesso em: 05/07/2012.

UNIVERSIDADE PAULISTA - UNIP. Matriz Curricular do Curso Superior de Tecnologia em Gestão Portuária. Disponível em:<http://www.unip.br/ensino/graduacao/tecnologicos/gestao_portuaria _grade.aspx >. Acesso em: 05/07/2012.

Suellem Deodoro Silva (suellem_04@hotmail.com) - Instituto Nacional de Pesquisas Hidroviárias INPH

Pítias Teodoro (pitiasteodoro@yahoo.com.br) - Programa de Engenharia de Transportes COPPE/UFRJ

Márcio de Almeida D'Agosto (dagoto@pet.coppe.ufrj.br) - Programa de Engenharia de Transportes - COPPE/UFRJ 